Bangladesh Med Res Counc Bull 2008; 34: 1-11

Copyright $\odot 2008$ by Bangladesh Medical Research Council

\title{
rt-PCR method for diagnosis and follow-up of hematological malignancies: first approach in Bangladesh
}

\author{
Tanvira Afroze Sultana ${ }^{1}$, Md. Abdul Mottalib ${ }^{1}$, Md. Sirazul Islam ${ }^{1}$, \\ Mohiuddin Ahmed Khan ${ }^{2}$ and Subhagata Choudhury ${ }^{1}$ \\ ${ }^{1}$ Laboratory Department, Bangladesh Institute of Research and Rehabilitation in Diabetes, Endocrine and \\ Metabolic Disorders (BIRDEM), Shahbag, Dhaka, ${ }^{2}$ Department of Hematology, Dhaka Medical \\ College,Dhaka,Bangladesh.e-mail: tanvira_sultana@yahoo.com
}

\begin{abstract}
Nested reverse-transcriptase polymerase chain reaction (rt-PCR) was performed on 58 leukemia patients at BIRDEM Laboratory, as a pioneering work in Bangladesh. Thirty of them were examined for the presence of BCR-ABL being clinically and morphologically diagnosed as chronic myeloid leukemia (CML) and 28 for PML-RAR $\alpha$ fusion transcripts being clinically and morphologically diagnosed as acute promyelocytic leukemia (APL/ AML M3). The cases were selected for targeted therapy with imatinib mesylate and all-Trans retinoic acid (ATRA) to treat CML and APL respectively. Samples were received either before commencement or during therapy. In the positive cases, amplified DNA products were visible after gel electrophoresis and were reported accordingly. In case of BCR-ABL, positive results were found for five out of six $(83.33 \%)$ untreated cases and 11 out of $24(45.83 \%)$ treated cases. Positive results for PMLRAR $\alpha$ were found for 12 out of $14(85.70 \%)$ untreated cases and 11 out of $16(68.75 \%)$ treated cases. A strong positive correlation was found between duration of treatment and negativity of PCR results in both the cases. In present times, the detection of minimal residual disease in patients undergoing treatment for hematological malignancies has become an important goal, not only to monitor the effectiveness of therapy but also to detect an impending relapse. This is the first time in Bangladesh that rt-PCR method is being employed to detect or monitor the presence of abnormal fusion genes in hematological malignancies.
\end{abstract}

\section{Introduction}

Diagnosis of hematological malignancies is not complete unless morphological examination is supplemented by further studies like immunophenotyping, karyotyping (conventional cytogenetics) and/or molecular studies, etc. Chronic myeloid leukemia (CML) and acute promyelocytic leukemia (APL) are two prototypes of such diseases. Molecular methods such as fluorescence in situ hybridization (FISH), reverse-transcriptase polymerase chain reaction (rt-PCR), and real-time quantitative rt-PCR have been used to detect the chimeric genes in question or their transcripts. Detection of specific chromosomal translocations is not only a diagnostic tool but is also a strategy to assess the response of individual patients to therapeutic interventions, and to evaluate treatment efficacy by monitoring residual disease. Among the various cytogenetic and molecular tests available for diagnosis and monitoring of hematological malignancies, polymerase chain reaction (PCR) based amplification assays are the most sensitive of all laboratory approaches, followed by flow cytometry, FISH, and cytogenetics, with associated detection thresholds of about one in one million, one in several thousand, one in several hundred, and one in 20 , respectively ${ }^{1}$.

Generally, conventional cytogenetics is the recommended test for detecting chromosomal aberrations in the form of specific translocations in newly diagnosed leukemia patients. However, cytogenetic analysis requires viable marrow cells or more than $10 \%$ blasts in the peripheral blood to reliably culture the cells and visualize metaphases. Occasionally fibrosis interferes with marrow aspiration, yielding few analyzable metaphase cells. The number of cells examined determines the sensitivity of karyotyping. A typical examination of 20 cells carries a detection rate of one affected cell among 20 cells, i.e. 5\%. Moreover, as the results 
may vary largely depending on expertise, manual errors are more likely.

FISH allows detection of translocations in either metaphase or interphase cells. Typically, 200 interphase or metaphase nuclei are evaluated, yielding a detection rate of about 1 in 200 , or $0.5 \%$. At present, FISH technology is not yet available in Bangladesh.

Southern blot analysis reliably identifies a certain gene rearrangement using probes targeting the specified breakpoint. The Southern blot method suffers from high cost and slow turnaround time. In addition, the assay is not sensitive for detecting minimal residual disease since tumor levels below about $5 \%$ are not detectable.

$\mathrm{rt}-\mathrm{PCR}$ is the most sensitive method described to date for detecting chromosomal translocations in hematological malignancies. Instead of targeting chromosomal DNA, the assay targets the more abundant chimeric RNA transcripts produced from the fused genes. Chromosomal DNA is an impractical target not only because it is less abundant than RNA but also as the breakpoint regions span such large segments of intronic DNA that multiple PCR primer sets would be required to detect every possible translocation. On the other hand, the chimeric RNA is remarkably homogeneous from case to case, thus allowing reliable detection of nearly all disease-associated translocations.

Amplification assays are capable of detecting one affected cell among 100,000 or so normal cells, a sensitivity unparalleled by any other available method $^{1-3}$. PCR has thus attracted much attention due to the extreme sensitivity and specificity of the technique.

The exceptional sensitivity of rt-PCR makes it well suited for assessing minimal residual disease following therapy. rt-PCR can be applied for detection of a wide range of fusion transcripts found in hematological malignancies. Among them, World Health Organization (WHO) has selected four fusion transcripts as significant markers for monitoring prognosis. They are, BCR-ABL $[\mathrm{t}\{9 ; 22\}]$ for CML and PML-RAR $\alpha[\mathrm{t}\{15 ; 17\}]$ for AML M3 or APL, AML-MTG8 [t $\{8 ; 21\}]$ for AML $\mathrm{M} 2$, and CBF $\beta-\mathrm{MYH} 11[\mathrm{inv} 16\}]$ for AML M4Eo ${ }^{4}$. We have been performing PCR for all four of these markers but as targeted therapy is available in the first two instances, namely imatinib mesylate (STI571) for CML and all-Trans retinoic acid (ATRA) for APL, they have more value to the physician in terms of therapeutic implications and in this setting we are thus publishing the data pertaining to those two transcripts only.

Qualitative rt-PCR, specially nested PCR, has been proved to improve our ability to measure residual disease and to forecast risk of relapse in CML and $\mathrm{APL}^{5-10}$. Several clinical trials are underway to further determine the utility and recommended frequency of laboratory monitoring of CML and APL, particularly now since targeted therapy is available. Interestingly, one mechanism of imatinib resistance in CML is amplification of the BCRABL chimeric gene, leading to over expression of the fusion transcript rather than the anticipated decrease expected with successful therapy ${ }^{11}$. This heralds the idea that alternative strategies for treatment may be considered once an rt-PCR negative patient on imatinib therapy becomes positive.

Real-time quantitative rt-PCR techniques are also now available that permit quantitative analysis of chimeric transcripts. Levels can be reported either in absolute terms or relative to a housekeeping transcript. Recent studies using this technology to detect BCR-ABL or PML-RAR $\alpha$ transcripts have shown good correlation with the results of cytogenetic analysis, FISH, Southern blot analysis, and conventional nested rt-PCR ${ }^{12-14}$. Various platforms such as the ABI Prism 7700 (Applied Biosystems, Foster City, CA) or the LightCycler (Roche Diagnostics, Indianapolis IN) were able to reproducibly detect one positive cell from among 10,000 to 100,000 normal cells ${ }^{12-20}$. The drawback in our country is that the initial setup including the machine is quite expensive. Moreover, standardization of results is very important for accurate interpretation. On the other hand, the set up for qualitative PCR is relatively less costly and easy to interpret as it only gives an objective result. Therefore, as an initial approach, we have felt that it was essential to establish qualitative rt-PCR in our country. Our aim was to detect the presence of fusion mRNA transcripts in CML and APL, either prior to treatment as an aid to confirmation of diagnosis, or during the course of treatment, to follow-up and detect any residue of leukemia cells after hematological remission was achieved.

\section{Materials and Methods}

Patient samples: The entire study was carried out in Hematology Section of Laboratory Department, Bangladesh Institute of Research and Rehabilitation in Diabetes, Endocrine and Metabolic Disorders (BIRDEM). Heparinized bone marrow or 
peripheral blood samples were collected after informed consent, from 58 patients provisionally diagnosed as leukemia and five non-leukemic subjects with apparently normal bone marrow findings (control subjects). Median age of the patients was 31 years (range 10 to 55 years). A summary of the clinical data of these patients is presented in Table I. The diagnosis and classification of the AML and CML patients were based on morphology according to WHO classification. Morphology was examined by Wright's staining. The patients included 25 patients morphologically diagnosed as CML, 15 as APL, and one as acute leukemia by the referring clinicians. Samples of 17 patients had been collected prior to initiation of therapy, among which seven were tested for BCR/ABL and 10 for PML/RAR $\alpha$. The rest of the patients had been receiving either conventional or targeted therapy for their specific malignancies. Samples of five patients (patient 6, 8, 18, 23 and 26) were investigated twice each at various intervals during their treatment tenure.

Fifteen CML patients received imatinib mesylate, a tyrosine kinase inhibitor, at the dose of 400 to 600 mg daily. The conventional chemotherapy regimens included hydroxurea, interferon $\gamma$, purinethal etc, as decided by the treating physician. Out of the APL patients, six patients had received all-Trans retinoic acid (ATRA) for more than three months, and one patient for 14 days. All of the APL patients had received conventional chemotherapy in combination with the targeted therapy that comprised of various cycles of daunorubicin, mitoxantron, purinethal and methotrexate, according to the justification of the treating physician. A complete hematological remission was defined as a WBC count of $<10 \times 10^{9} / \mathrm{L}$, a platelet count of $<450 \times 10^{9} / \mathrm{L}$, no immature cells (blasts, promyelocytes, myelocytes) in the peripheral blood, and disappearance of all signs and symptoms related to leukemia (including palpable splenomegaly) lasting for at least four weeks. A complete molecular response was defined as undetectable levels of BCR-ABL confirmed by nested PCR.

Both in case of CML or APL, the patients were divided into four groups, Group I, freshly diagnosed and sample taken before commencement of treatment, Group II, having received less than three months of treatment, Group III, as those treated for three to six months and Group IV, as those treated for more than six months.

PCR amplification of BCR/ABL or MYL/ RAR (PML/RAR $\alpha$ ) junctions: Total cellular RNA was isolated from appropriate amounts of bone marrow or peripheral blood samples that contained from $2 \mathrm{x}$ $10^{6}$ to $1 \times 10^{7}$ leucocytes using a commercial kit (QIAamp RNA Blood Mini Kit; QIAGEN GmbH, Germany) according to the manufacturer's conditions. Concentration of RNA was measured spectrophotometrically and the ratio of optical density at 260 and $280 \mathrm{~nm}$ checked. A ratio of 1.80 to 2.00 was accepted as good quality RNA and any sample not achieving this target was discarded. In vitro reverse transcription of $1 \mu \mathrm{g}$ or less of total

Table I. Clinical data of patients selected for rt-PCR

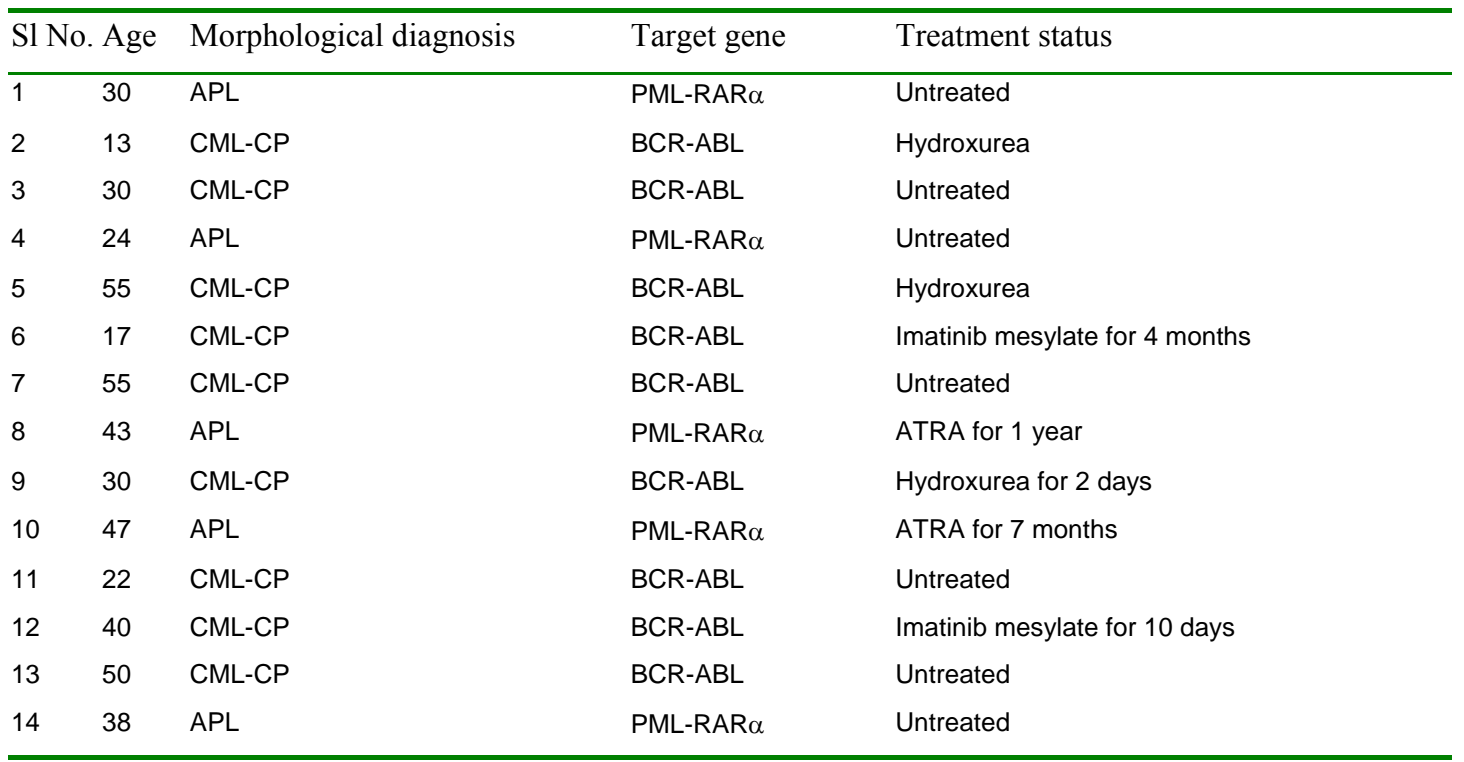




\begin{tabular}{|c|c|c|c|c|}
\hline 15 & 36 & APL & PML-RAR $\alpha$ & ATRA for 6 months \\
\hline 16 & 33 & CML-CP & BCR-ABL & Imatinib mesylate for 1 year \\
\hline 17 & 55 & CML-CP & BCR-ABL & Untreated \\
\hline 18 & 50 & APL & PML-RAR $\alpha$ & ATRA for 7 days \\
\hline 19 & 24 & CML-CP & BCR-ABL & Imatinib mesylate for 8 months \\
\hline 20 & 35 & CML-CP & BCR-ABL & Imatinib mesylate for 7 Months \\
\hline 21 & 34 & CML-CP & BCR-ABL & Imatinib mesylate for 9 Months \\
\hline 22 & 36 & CML-CP & BCR-ABL & Imatinib mesylate for 8 Months \\
\hline 23 & 24 & APL & PML-RAR $\alpha$ & Untreated \\
\hline 24 & 44 & APL & PML-RAR $\alpha$ & ATRA for 14 days \\
\hline 25 & 18 & APL & PML-RAR $\alpha$ & Untreated \\
\hline 26 & 25 & APL & PML-RAR $\alpha$ & ATRA for 3 days \\
\hline 27 & 60 & CML-CP & BCR-ABL & Imatinib mesylate for 3 Months \\
\hline 28 & 22 & CML-CP & BCR-ABL & Imatinib mesylate for 10 months \\
\hline 29 & 28 & APL & PML-RAR $\alpha$ & Untreated \\
\hline 30 & 27 & CML-CP & BCR-ABL & IFN+Hydrea+Purinethal, to start Imatinib \\
\hline 31 & 7 & AL, probably AML/ CML-AP & BCR-ABL & Untreated \\
\hline 32 & 38 & CML-CP & BCR-ABL & Imatinib for 4 months \\
\hline 33 & 50 & CML-CP & BCR-ABL & Imatinib for 18 months \\
\hline 34 & 27 & CML-CP & BCR-ABL & Imatinib for 2 months \\
\hline 35 & 29 & APL in hematological remission & PML-RAR $\alpha$ & Dauno+Mit+ATRA for 1 month \\
\hline 36 & 40 & APL in hematological remission & PML-RAR $\alpha$ & 6 cycle of chemo+ ATRA for 7 months \\
\hline 37 & 32 & $\mathrm{CML}$ in hematological remission & BCR-ABL & Imatinib for 4 months \\
\hline 38 & 46 & $\mathrm{CML}$ in hematological remission & BCR-ABL & Imatinib for 15 months \\
\hline 39 & 20 & APL & PML-RAR $\alpha$ & Untreated \\
\hline 40 & 23 & $\mathrm{CML}$ in hematological remission & BCR-ABL & Imatinib for 4 months \\
\hline 41 & 24 & APL in hematological remission & PML-RAR $\alpha$ & ATRA for 3 months \\
\hline 42 & 50 & APL in hematological remission & PML-RAR $\alpha$ & ATRA for 7 months \\
\hline 43 & 40 & APL & PML-RAR $\alpha$ & Untreated \\
\hline 44 & 38 & CML-CP & BCR-ABL & Untreated \\
\hline 45 & 10 & APL & PML-RAR $\alpha$ & Untreated \\
\hline 46 & 25 & APL in hematological remission & PML-RAR $\alpha$ & ATRA for 4 months \\
\hline 47 & 20 & APL & PML-RAR $\alpha$ & Untreated \\
\hline 48 & 28 & AML & PML-RAR $\alpha$ & Untreated \\
\hline 49 & 44 & AML & PML-RAR $\alpha$ & Treated for 3 years (ATRA +$)$ \\
\hline 50 & 7 & CML & BCR-ABL & Hydrea for 2 month \\
\hline 51 & 30 & CML & BCR-ABL & Hydra for 1 Week \\
\hline 52 & 30 & APL & PML-RAR $\alpha$ & Fresh \\
\hline 53 & 28 & AML & PML-RAR $\alpha$ & Untreated \\
\hline 54 & 25 & AML & PML-RAR $\alpha$ & Untreated \\
\hline 55 & 17 & AML & PML-RAR $\alpha$ & Vasonoid for 3 days \\
\hline 56 & 50 & $\mathrm{CML}$ in hematological remission & BCR-ABL & Enliven for 3 months \\
\hline 57 & 25 & AML M4 & PML-RAR $\alpha$ & Untreated \\
\hline 58 & 5.5 & ?CML & BCR-ABL & Untreated \\
\hline
\end{tabular}


RNA to cDNA was performed in a $20 \mu 1$ volume for $15 \mathrm{~min}$ at $42^{\circ} \mathrm{C}$ containing Quantiscript reverse transcriptase and a mixture of both oligo-dT and random hexamers as primers, using a commercial kit (Quantitect Reverse Transcription Kit; QIAGEN GmbH, Germany) according to the manufacturer's conditions. The reverse transcript-tase included in the kit is a mix of Omniscript and Sensiscript Reverse Transcriptases, which are recombinant of PCR mixture containing $1.5 \mathrm{mmol} / \mathrm{L} \mathrm{MgCl}_{2}, 50$ $\mathrm{mmol} / \mathrm{L} \mathrm{KCl}, 10 \mathrm{mmol} / \mathrm{L}$ Tris-HCl, pH 8.3, 200 $\mu \mathrm{mol} / \mathrm{L}$ dNTP, $2.5 \mathrm{U}$ of HotStartaq Polymerase and $400 \mathrm{nmol} / \mathrm{L}$ of primers. The temperature conditions for each individual primer set are shown in Table II. At the end, $1 \mu \mathrm{l}$ of first PCR product was used for a second round of amplification for further 30 cycles using a nested primer. The sequences of forward and reverse oligonucleotide primers used for major, minor and micro $\mathrm{BCR} / \mathrm{ABL}$, PML/RAR $\alpha \beta$-actin amplifica-tion were received as a kind courtesy from the Department of Hematology and Oncology, Hiroshima University, Japan and are shown in Table III. Finally, $10 \mu \mathrm{l}$ of PCR product was run on a $2 \%$ molecular biology grade agarose gel stained with ethidium bromide and visualized under a UV transilluminator (Optima UVP, Japan) at $365 \mathrm{~nm}$. As positive controls, either cell lines or cDNA from samples previously found positive for the respective translocations, were used. The names of the positive control cell lines are provided in Table III. Amplification of $\beta$-actin mRNA was always performed with $1 \mu \mathrm{l}$ of the same cDNA preparation used to identify the respective translocations, and thus, presence of good quality cDNA was ensured.

Table II: Thermal cycling programs for first and nested PCR major, minor and micro BCR-ABL

\begin{tabular}{lll}
\hline Initial activation of Taq Polymerase & $15 \mathrm{~min}$ & $95^{\circ} \mathrm{C}$ \\
& & \\
\hline 3-step cycling & & \\
Denaturation & $30 \mathrm{~s}$ & $94^{\circ} \mathrm{C}$ \\
Annealing & $30 \mathrm{~s}$ & $55^{\circ} \mathrm{C}$ \\
Extension & $1 \mathrm{~min}$ & $72^{\circ} \mathrm{C}$ \\
Number of cycles & 30 & \\
Final extension & $7 \mathrm{~min}$ & $72^{\circ} \mathrm{C}$ \\
\hline
\end{tabular}

PML-RAR $\alpha$

\begin{tabular}{lll}
\hline Initial activation of Taq Polymerase & $15 \mathrm{~min}$ & $95^{\circ} \mathrm{C}$ \\
\hline 3-step cycling & & \\
Denaturation & $1 \mathrm{~min}$ & $95^{\circ} \mathrm{C}$ \\
Annealing & $1 \mathrm{~min}$ & $50^{\circ} \mathrm{C}$ \\
Extension & $1 \mathrm{~min}$ & $72^{\circ} \mathrm{C}$ \\
Number of cycles & 30 & \\
Final extension & $7 \mathrm{~min}$ & $72^{\circ} \mathrm{C}$ \\
\hline
\end{tabular}

Interpretation of results: The expected product size of major BCR-ABL, was either 446 base pairs (bp) when the breakpoint on BCR gene is on exon 14 and $371 \mathrm{bp}$ when the breakpoint is on exon 13 with the primer sets used in our laboratory ${ }^{21}$. The expec-

Table III: Sequences of primers

\begin{tabular}{|c|c|c|c|c|c|c|}
\hline & Gene & & Name & Primer sequence & Product size & $\begin{array}{l}\text { Positive control } \\
\text { cDNA }\end{array}$ \\
\hline \multirow[t]{4}{*}{1} & \multirow{4}{*}{$\begin{array}{l}\text { Major BCR- } \\
\mathrm{ABL}\end{array}$} & \multirow[t]{2}{*}{1 st } & BCR1 & 5'-GCTTCTCCCTGACATCCGTG-3' & & \multirow{4}{*}{$\begin{array}{l}\text { KT1 1840 } \\
\text { (e13a2) B3 } 2415 \\
(\mathrm{e} 14 \mathrm{a} 2)\end{array}$} \\
\hline & & & ABL1 & 5'-GGCCCATGGTACCAGGAGTG-3' & & \\
\hline & & \multirow[t]{2}{*}{ 2nd } & $\mathrm{BCR} 2$ & 5'-GGAGCTGCAGATGCTGACCAAC-3' & \multirow{2}{*}{$\begin{array}{l}446 \mathrm{bp}(\mathrm{e} 14 \mathrm{a} 2) \\
371 \mathrm{bp}(\mathrm{e} 13 \mathrm{a} 2)\end{array}$} & \\
\hline & & & ABL2 & 5'-GTTTCTCCAGACTGTTGACTG-3' & & \\
\hline \multirow[t]{4}{*}{2} & \multirow{4}{*}{$\begin{array}{l}\text { minor BCR- } \\
\mathrm{ABL}\end{array}$} & \multirow[t]{2}{*}{1 st } & BCR3 & 5'-CGCATGTTCCGGGACAAAAGC-3' & & \multirow[t]{4}{*}{ Hirata 2834} \\
\hline & & & ABL1 & & & \\
\hline & & \multirow[t]{2}{*}{ 2nd } & BCR4 & 5'-CGCTCTCCCTCGCAGAACTC-3' & \multirow[t]{2}{*}{$472 \mathrm{bp}$} & \\
\hline & & & ABL2 & & & \\
\hline \multirow[t]{4}{*}{3} & \multirow[t]{4}{*}{ micro BCR-ABL } & \multirow[t]{2}{*}{1 st } & BCRc30+ & 5'-AGAGGTCCAAGGTGCCCTAC-3' & & \multirow[t]{4}{*}{$\times$} \\
\hline & & & ABL1 & & & \\
\hline & & \multirow[t]{2}{*}{ 2nd } & BCRc31+ & 5'-CGGACATCCAGGCACTGAAG-3' & \multirow[t]{2}{*}{329 bp } & \\
\hline & & & ABL2 & & & \\
\hline \multirow[t]{3}{*}{4} & \multirow[t]{3}{*}{ PML-RAR $\alpha$} & \multirow[t]{2}{*}{1 st } & PML M4 & $\begin{array}{l}\text { 5'-AGCTGCTGGAGGCTGTGGA } \\
\text { CGCGCGGTACC-3' }\end{array}$ & & \multirow[t]{3}{*}{ Kimura 1224} \\
\hline & & & RARa R5 & 5'-CCACTAGTGGTAGCCTGAGGACT-3' & & \\
\hline & & 2nd & PML M4 & & $400-700 \mathrm{bp}$ & \\
\hline
\end{tabular}




\begin{tabular}{|c|c|c|c|c|c|}
\hline & & & RARa R8 & $\begin{array}{l}\text { 5'-CAGAACTGCTGCTCTG } \\
\text { GGTCTCAAT-3' }\end{array}$ & \\
\hline \multirow[t]{4}{*}{5} & \multirow{4}{*}{$\begin{array}{l}\text { PML-RAR } \alpha \\
\text { (alternative) }\end{array}$} & \multirow[t]{2}{*}{1 st } & PML M2 & 5'-AGTGTACGCCTTCTCCATCA-3' & \\
\hline & & & RARa R5 & 5'-CCACTAGTGGTAGCCTGAGGACT-3' & \\
\hline & & \multirow[t]{2}{*}{ 2nd } & PML M2 & & \multirow[t]{2}{*}{ 200-400 bp. } \\
\hline & & & RARa R8 & $\begin{array}{l}\text { 5'-CAGAACTGCTGCTCTGG } \\
\text { GTCTCAAT-3' }\end{array}$ & \\
\hline
\end{tabular}

ted product sizes for minor and micro $\mathrm{BCR} / \mathrm{ABL}$ were $472 \mathrm{bp}$ and $329 \mathrm{bp}$ respectively. In case of PML/RAR $\alpha$, due to alternative splicing of the breakpoint cluster regions (BCR) on myl locus of chromosome 15, PCR products of various sizes ranging from 400 to $700 \mathrm{bp}$ were found with M4 primer which is found to be a "universal primer" for all the three forms of translocations seen in APL (short isoform: intron 3-bcr 3; long variant isoform: exon 6-BCR 2; and long isoform: intron 6-BCR 1) ${ }^{16-18}$. A single product of either $326 \mathrm{bp}$ or $290 \mathrm{bp}$ was observed with $\mathrm{m} 2$ primer, that corresponded to the translocation breakpoints intron 6-BCR 1 and exon 6-BCR 2 respectively ${ }^{8,22,23}$. No band was seen with $\mathrm{m} 2$ primer when the breakpoint lay in the intron 3-BCR 3 region of myl locus. Accordingly, the results of nested PCR for BCR/ABL were interpreted as major, minor or micro isoform and for PML/RAR alpha as long (1), long variant (v) isoform or short (s) isoform.

\section{Results}

RNA isolated from bone marrow or peripheral blood samples of 26 patients were examined for the presence of the BCR-ABL and 24 for PML-RAR $\alpha$ fusion transcript.

PML-RAR $\alpha$ : The patients examined for PMLRAR $\alpha$ were diagnosed either as acute myeloid leukemia or APL by morphology.

Group I: 14 patients belonged to this group, who had been provisionally diagnosed as APL and the samples collected prior to initiation of therapy. All of the 10 samples came out to be positive (10/10) for PML-RAR $\alpha$ by nested PCR. Therefore, there was a strong concurrence between morphological impression and the results of PCR in these cases.

Group II: One patient (patient 35) had been receiving treatment comprising of conventional chemotherapy along with ATRA, for less than three months. The sample showed presence of PMLRRA $\alpha$ fusion transcripts.

Group III: Three patients (patient 15, 41 and 46) fell in this group. The results were positive in all $(3 / 3)$ the cases. Two out of three patients (patient 41 and 46) had been examined prior to treatment (patient 23 and 26) and had been found positive for PML-RAR $\alpha$ in that instance also.

Group IV: Five patients were included in this group. All of them had received ATRA alone or in combination with other conventional chemotherapeutic drugs. Two $(2 / 5)$ were found negative and three (3/5) positive by nested PCR. Between the two negative cases, one (patient 42) had been examined previously (patient 18) at the time of commencement of therapy and had been positive at that time (Figure 1). Among the three positive cases, one (patient 49) had been examined prior to therapy (patient 8) and had been positive at that time too.

$B C R-A B L$ : Among the cases examined for BCRABL, 25 had provisionally been diagnosed as suffering from CML, and one as acute leukemia.

Group I: There were 10 patients in this group, seven morphologically compatible with CML and one with acute leukemia with more than $50 \%$ of blasts. All the seven CML cases showed presence (7/7) of major BCR-ABL transcripts. The one acute leukemia patient showed absence $(0 / 1)$ of any of the three BCR-ABL transcripts (major, minor or micro BCR-ABL). Therefore, the results of molecular analysis correlated strongly with the morphological appearance.

Group II: Two patients (patient 2 and 34) had received treatment for less than three months. Between them, one (patient 2) was receiving hydroxurea only and had not achieved hematological remission. The other one (patient 34) was receiving imatinib mesylate and was in hematological remission. Both the patients (2/2) were found positive for BCR-ABL by nested PCR. 

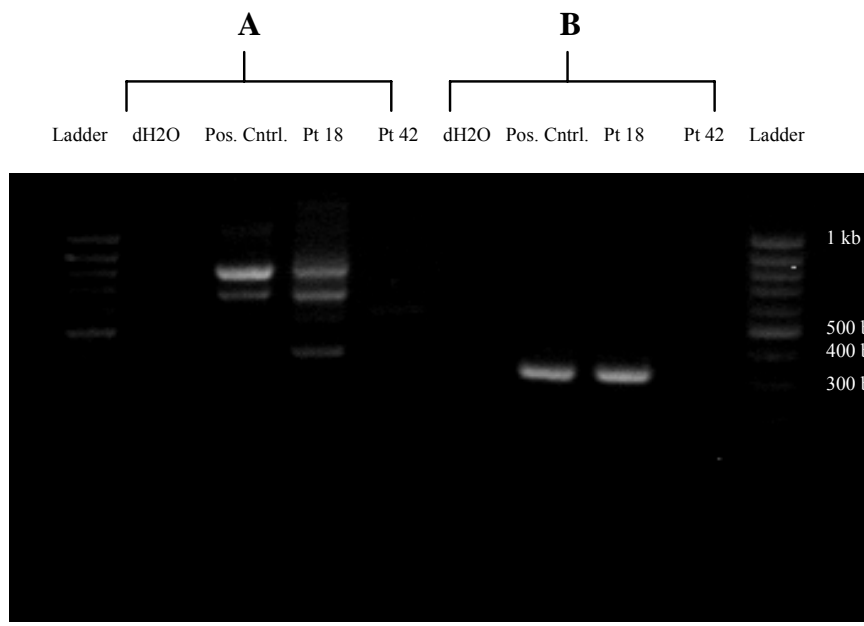

Band size 326 base pairs for positive control and patient 18 ; no band for patient 42 .

Figure 1: PCR amplification of the myl/RAR $\alpha$ junction of an APL patient prior to treatment (patient 18) and the same patient after six months of therapy (patient 42) with All-trans Retinoic Acid (ATRA). Primers M4 (A) or M2 (B) and R5 were used as a first cycle of PCR; then a second round of amplification was performed by using R8 as nested primer. The first sample (patient 18) showed a BCR 1 type of PML/RAR alpha fusion transcript with a band size of 326 bp by the M2/R8 set of primers (B), which disappeared after treatment for six months.

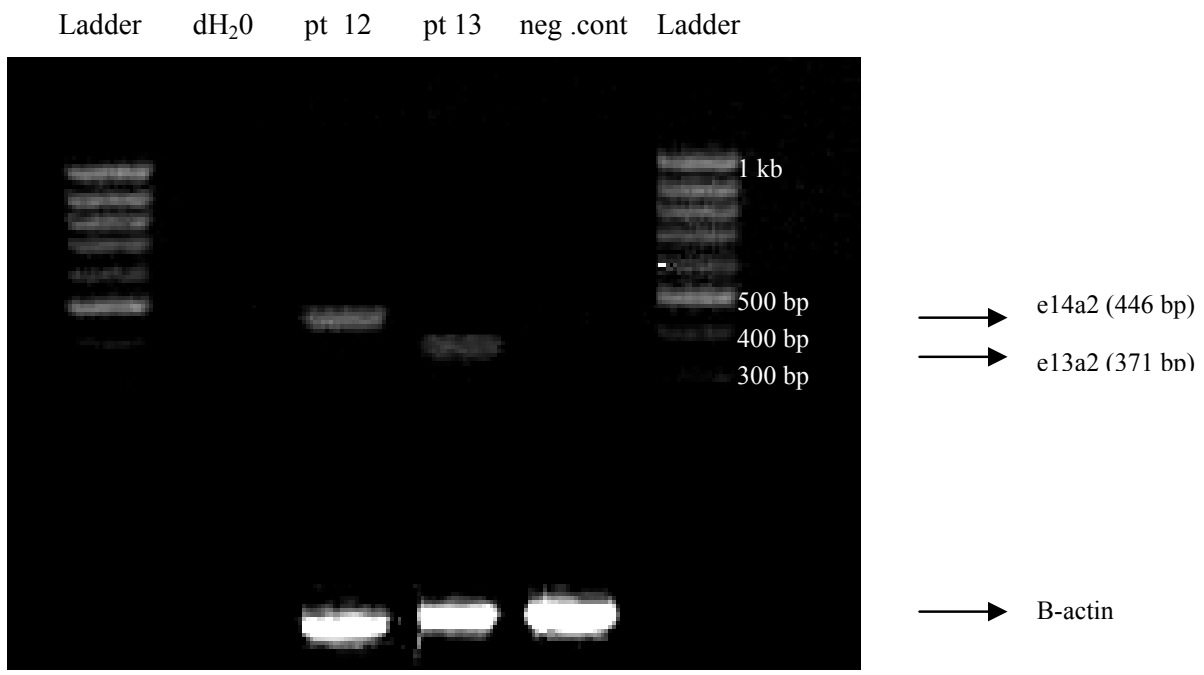

Figure 2: Nested rt-PCR for BCR-ABL. Patient 12 shows the e14a2 isoform of major BCR-ABL (product size 446 bp) and patient 13 shows the $13 \mathrm{a} 2$ isoform ( $371 \mathrm{bp}$ ) while cDNA isolated from a normal control person shows no amplification of the BCR-ABL fusion transcript. The bands below are rt-PCR products for the $\beta$-actin mRNA.

Group III: There were nine patients in this group. Karyotyping had been attempted in four of these cases, with a negative result in one case and sample turned out to be inadequate for analysis in three cases. Four of the patients had not achieved hematological remission and five were in complete hematological remission (CHR). Accordingly the patients were subdivided into two groups, Group III A and Group IIIB respectively. In Group IIIA, two patients were receiving (patient 21 and 22) imatinib mesylate while the other two (patient 5 and 30) were on conventional chemotherapy regimen. All four of the patients in Group IIIA were positive (4/4) for major BCR-ABL. Among them, one was found to be negative for Philadelphia chromosome by conventional karyotyping. In Group IIIB, all of the patients were receiving imatinib mesylate. Two of the patients (patient 6 and 32) were positive $(2 / 5)$ for major BCR-ABL and the rest of the three $(3 / 5)$ were negative. Therefore the molecular responses according to our tests, correlated well with the hematological profiles of the patients.

Group IV: Six patients belonged to this group. Five of them turned out to be negative $(5 / 6)$ for any of 
the three isoforms of BCR-ABL fusion transcripts. One (patient 38) was positive for minor BCR-ABL. In this case also, there was a strong correlation between the hematological response and results of our tests.

Overall, among the cases positive for major BCRABL, both the two isoforms (e13a2 and e14a2) were found among our cases (Figure 2). Three cases possess the e13a2 for while the rest had the e14a2 isoform.

\section{Discussion}

Recent advances in molecular genetics impact the health care and outcome of patients with hematological malignancies. BCR-ABL, a common molecular defect in CML, and PML-RAR $\alpha$ in APL, are valuable tumor markers whose detection influences prognosis and clinical management decisions. Analysis of tumor-specific translocations is a promising means for evaluating minimal residual disease in those patients whose tumor harbors a translocation for which a reliable laboratory assay is available. Accordingly, we performed rt-PCR in patients morphologically suspected to be suffering from leukemia, either for confirmation of diagnosis in untreated cases or to detect residual disease in treated ones. We took a nested PCR approach and restricted ourselves to qualitative analysis only, as an initial step.

PML-RAR $\alpha$ : According to duration of treatment of ATRA, we classified the treated cases into four groups. The first group was newly diagnosed and had not received any treatment at all. There were 14 patients morphologically suspected to be suffering from APL, who had not received treatment. Twelve of them were positive for PMLRAR $\alpha$ by our method while two were negative. The two negative cases may be harboring a translocation different from PML-RAR $\alpha$, like promyelocytic leukemia zinc finger PLZF-RAR $\alpha\{t$ $(11 ; 17)(\mathrm{q} 23 ; \mathrm{q} 21)\}$ that is occasionally found in APL $^{24,25}$. This could not be confirmed, as we did not have any means of identifying the latter translocation. On the other hand, two other cases that were suspected to have morphology of AML other than M3 were also tested for the presence of PML-RAR $\alpha$, and one found to be positive and the other negative. The positive one contained monocytoid blasts in bone marrow and PBF, which may be a variant form of APL with hypogranular promyelocytes. The other one had been provisionally diagnosed as AML M4.

The second had received treatment for less than 35 days. According to the observation of National
Comprehensive Cancer Network (NCCN), molecular remission is not achieved before 35 days $^{26}$. There were four cases in this group. All were found PCR-positive by our method, which is comparable to the observation of other researchers including NCCN.

The third group had received treatment for more than 35 days but had not received more than 3 cycles of consolidation chemotherapy. Two cases fell in this group, both of which were found positive. Though a molecular remission may be achieved within this time, it has been observed in many clinical trials that it may not always be achieved before 2-3 courses of consolidation ${ }^{26}$. Therefore it may be too early to classify these as induction failure; rather they may be kept under follow-up for molecular residual disease.

The fourth group had received treatment for more than six months, including more than 3 cycles of consolidation and all were in hematological remission. Four (4/6) cases were found PCR positive while two $(2 / 6)$ were found PCR negative. Further follow-up by PCR as well as clinical observation for relapse is required to correlate the results with the prognosis of the patients.

Biondi et $\mathrm{al}^{8}$ have shown that PCR amplification of the PML/RAR $\alpha$ gene is an easy and rapid method for detection and monitoring of the malignant clone in APL. Moreover, it has been seen that achievement of negative $\mathrm{rt}$-PCR in remission is associated with favorable RFS and OS. Continuous negative rt-PCR results are associated with longterm relapse-free survival and may be considered as potentially curative ${ }^{9}$. Other researchers have supported this data ${ }^{10,27-30}$.

$B C R-A B L$ : Molecular monitoring provides valuable information for the follow-up of patients with CML in chronic phase treated with imatinib. Achieving a major molecular response correlated with an improved probability of a durable cytogenetic remission, particularly when achieved early during the course of therapy. Most major molecular remissions have been durable, and increases in BCR-ABL transcripts have not translated in loss of cytogenetic remission for most patients with molecular response. Thus, a major goal of therapy with imatinib should be to achieve an early major molecular response.

We divided the patients examined for BCR-ABL into four groups according to their treatment status. The first group consisted of six patients with morphology compatible with CML-CP, who had not received treatment. Five $(5 / 6)$ were PCR positive for major BCR-ABL and one was 
negative. The negative one may be atypical CML (aCML), which has been included in the new WHO classification of leukemia ${ }^{4}$ or may not be CML at all.

Alongside, we had analyzed two other untreated cases, which were clinically suspected by various clinicians to be suffering from CML, but the morphology at the time of collection of the sample did not resemble the disease. Both $(2 / 2)$ were negative for PCR. Therefore, the test may be helpful in excluding a diagnosis like malignancy when a leucocytosis presented by a patient might be reactive only. This will help avoid exposure to toxic drugs as well as undue expenses and worry of the patents and their relatives.

The second group comprised of six patients who had received treatment, either imatinib mesylate or hydroxurea, but for duration of less than three months. Four (4/6) were PCR positive while two $(2 / 6)$ turned out to be negative. As the presence of Philadelphia chromosome had not been confirmed in any of the cases before commencement of therapy, the possibility remains that the negative two did not bear the aberrant chromosome at all. On the other hand, it can be said that it is too early to look for molecular remission before three months as observed by the positive cases ${ }^{31}$.

The third group had 10 patients who had received either imatinib mesylate or conventional chemotherapy, for three to six months. Four (4/10) had not achieved hematological remission while six $(6 / 10)$ had done so. All of the first four were PCR positive while among the other six, three $(3 / 6)$ were positive and the rest of the three (3/6) were negative. The question remains whether six months is also too early to declare them as treatment failure. According to the recent practice guidelines of NCCN, after hematological remission is achieved during treatment with imatinib mesylate, cytogenetics and rt-PCR should be done every three months for the first 2 years and every six months for the next three years. ${ }^{32}$ A search for kinase domain mutations is recommended if complete cytogenetic remission is not achieved after six months ${ }^{32}$.

The fourth group had six patients who had received imatinib Mesylate for more than six months and all were in hematological remission. All the six (6/6) were PCR negative. Therefore, it may be said that all were in molecular remission and the therapy had been effective.

Many investigators have reported, with varying results, on the detection of minimal residual disease by nested PCR in patients with CML. Roth et al ${ }^{6}$ analyzed 64 CML patients after allogeneic SCT and detected BCR-ABL transcripts at one time point in 37 of the patients. Of those 37,13 eventually had a disease relapse, with a median time to relapse of 5 months. No relapses were observed in patients with negative PCR results. Roth et $\mathrm{al}^{6}$ thus concluded that nested PCR could define subgroups of patients in apparent clinical remission but with an increased risk of disease recurrence. In contrast, Miyamura et $\mathrm{al}^{7}{ }^{7}$ also using nested PCR, detected no association between PCR positivity and subsequent relapse in their series of 64 patients with CML in remission after allogeneic SCT. In five cases, the persistence of detectable BCR-ABL transcript for up to 2 years post-remission did not result in disease recurrence. Hughes et al, ${ }^{33}$ on the basis of nested PCR results in $37 \mathrm{CML}$ patients in remission after allogeneic SCT, concluded that PCR positivity within 6 months after transplantation did not predict a worse outcome, whereas PCR positivity later than 6 months after transplantation did.

The PCR technique, although considered a valid clinical testing procedure, should be used cautiously as a laboratory test until sufficient data are available to show that it meets acceptable criteria of sensitivity, specificity, and positive and negative predictive values. How new PCR technologies such as "realtime" PCR quantification will solve these concerns and become a reliable tool for the clinician merits further investigation. On the horizon are gene expression profiles that will likely provide additional information beyond what is obtainable with current clinical and laboratory approaches.

\section{Acknowledgements}

We express our deepest gratitude to the Department of Hematology and Oncology, Research Institute for Radiation Biology and Medicine, Hiroshima University, Japan, for extending their kind support in establishing the tests and specially for providing the primers along with their sequences as an initial start up. Our special thanks goes to Mr Mukul Kumar Nandi, Deputy Chief Medical Technologist, BIRDEM Laboratory for his active technical support. We would also like to thank all hematologists and oncologists of Bangladesh who had sent their patients to us for investigations.

\section{References}

1. Nashed AL, Rao KW, Gulley ML. Clinical applications of BCR-ABL molecular testing in acute leukemia. J Mol Diagn. 2003; 5: 63-72.

2. Sklar J. Polymerase chain reaction: The molecular microscope of residual disease. J Clin Oncol. 1991; 9: 1521. 
3. Faderl S, Talpaz M, Kantarjian HM, Estrov Z. Should polymerase chain reaction analysis to detect minimal residual disease in patients with chronic myelogenous leukemia be used in clinical decision making? Blood 1999; 93: 2755-59.

4. Harris NL, Jaffe ES, Diebold J Flandrin G, MullerHermelink HK, Vardiman J, Lister TA, Bloomfield CD. The World Health Organization classification of neoplastic diseases of the hematopoietic and lymphoid tissues: Report of the clinical advisory committee meeting - Airlie House, Virginia, November 1997. Histopathology 2000; 36: 69-86.

5. Hughes TP, Morgan GJ, Martiat P, Goldman JM. Detection of residual leukemia after bone marrow transplant for chronic myeloid leukemia: Role of polymerase chain reaction in predicting relapse. Blood 1991; 7: 874.

6. Roth MS, Antin JH, Ash R, Terry VH, Gotlieb M, Silver SM, Ginsburg D. Prognostic significance of Philadelphia chromosome positive cells detected by the polymerase chain reaction after allogeneic bone marrow transplant for chronic myelogenous leukemia. Blood 1992; 79: 276.

7. Miyamura $\mathrm{K}$, Tahara $\mathrm{T}$, Tanimoto $\mathrm{M}$, Morishita $\mathrm{Y}$, Kawashima K, Morishima Y, Saito H, Tsuzuki S, Takeyama K, Kodera Y. Long persistent bcr-abl positive transcript detected by polymerase chain reaction after marrow transplant for chronic myelogenous leukemia without clinical relapse: A study of 64 patients. Blood 1993; 81:1089.

8. Biondi A, Rambaldi A, Pandolfi PP, Rossi V, Giudici G, Alcalay M, Coco FL, Diverio D, Enrico M, Pogliani, Eraldo M, Lanzi, Mandelli F, Masera G, Barbui T, Pelicci PG. Molecular monitoring of the $\mathrm{myl} /$ retinoic acid receptor-alpha fusion gene in acute promyelocytic leukemia by polymerase chain reaction. Blood 1992; 80: 492.

9. Jiong $\mathrm{H}$, Ting $\mathrm{Y}$, Weili $\mathrm{Z}$ Bowei $\mathrm{E}$, Zhixiang $\mathrm{E}$ Xiusong A, Guanlin E, Saijuan AE, Zhenyi O. Impact of rt-PCR monitoring on the long-term survival in acute promyelocytic leukemia. Chin Med J. 2000; 113: 899-902.

10. Fukutani H, Naoe T, Ohno R Yoshida H, Kiyol H, Miyawaki S, Morishita H,Sano F, Kamibayashi H, Matsue K. Prognostic significance of the rt-PCR assay of PML-RARA transcripts in acute promyelocytic leukemia. The Leukemia Study Group of the Ministry of Health and Welfare (Kouseisho). Leukemia 1995; 9: 588-93.

11. Gorre ME, Mohammed M, Ellwood K, Hsu N, Paquette R, Rao PN, Sawyers CL. Clinical resistance to STI-571 cancer therapy caused by BCR-ABL gene mutation or amplification. Science 2001; 293: 876-80.

12. Saffroy R, Lemoine A, Brézillon P, Frénoy N, Delmas B, Goldschmidt E, Souleau B, Nedellec G, Debuire B. Real-time quantitation of BCR-ABL transcripts in haematological malignancies. Eur J Haematol 2000; 65: 258-66.
13. Emig M, Saussele S, Wittor H, Weisser A, Reiter A, Willer A, Berger U, Hehlmann R, Cross NC, Hochhaus A. Accurate and rapid analysis of residual disease in patients with CML using specific fluorescent hybridization probes for real-time quantitative rt-PCR. Leukemia 1999; 13: 1825-32

14. Schoch C, Schnittger S, Kern W, Lengfelder E, Löffler $\mathrm{H}$, Hiddemann W, Haferlach T. Comparison of chromosome banding analysis, interphase- and hypermetaphase-FISH, qualitative and quantitative PCR for diagnosis and for follow-up in chronic myeloid leukemia: A study on 350 cases. Leukemia 2002; 16: 53-59

15. Eder M, Battmer K, Kafert S, Stucki A, Ganser A, Hertenstein B. Monitoring of BCR-ABL expression using real-time rt-PCR in CML after bone marrow or peripheral blood stem cell transplantation. Leukemia 1999; 13: 1383-89.

16. Kreuzer KA, Lass U, Bohn A, Landt O, Schmidt CA. LightCycler technology for the quantitation of bcr/abl fusion transcripts. Cancer Res. 1999; 59: 3171-74.

17. Amabile M, Giannini B, Testoni N, Montefusco V, Rosti G, Zardini C, Terragna C, Buonamici S, Ottaviani E, Soverini S, Fiacchini M, Bassi S, de Vivo A, Trabacchi E, Saglio G, Pane F, Baccarani M, Tura S, Martinelli G. Real-time quantification of different types of BCR-ABL transcript in chronic myeloid leukemia. Haematologica 2001; 86: 252-59.

18. Bolufer P, Sanz GF, Barragán E, Sanz MA, Cervera J, Lerma E, Senent L, Moreno I, Planelles MD. Rapid quantitative detection of $\mathrm{BCR}-\mathrm{ABL}$ transcripts in chronic myeloid leukemia patients by real-time reverse transcriptase polymerase-chain reaction using fluorescently labeled probes. Haematologica 2000; 85: 1248- 54.

19. Barbany G, Hagberg A, Olsson-Stromberg U, Simonsson B, Syvanen AC, Landegren U. Manifoldassisted reverse transcription-PCR with real-time detection for measurement of the BCR-ABL fusion transcript in chronic myeloid leukemia patients. Clin Chem. 2000; 46: 913-20.

20. Kreuzer KA, Lass U, Nagel S, Ellerbrok H, Pauli G, Pawlaczyk-Peter B, Siegert W, Huhn D. Applicability of an absolute quantitative procedure to monitor intraindividual bcr/abl transcript kinetics in clinical samples from chronic myelogenous leukemia patients. Int $\mathrm{J}$ Cancer 2000; 86: 741-46.

21. Chissoe SL, Bodenteich A, Wang Y, Wang YP, Burian D, Sandra W, Clifton, Crabtree J, Freeman A, Kala Iyer, Jian L, Yichen MA, Mclaury HJ, Pan HQ, Omayma H, Sarhan, Toth S, Wang Z, Zhang G, Heisterkamp N, Groffen J, Roe BA. Sequence and analysis of the human c-abl gene, the $b c r$ gene, and regions involved in the Philadelphia chromosomal translocation. Genomics 1995; 27, 67-82.

22. Dong S, Geng JP, Tong JH, Wu Y, Cai JR, Sun GL, Chen SR, Wang ZY, Larsen CJ, Berger R. Breakpoint clusters of the PML gene in acute promyelocytic leukemia: Primary structure of the reciprocal products 
of the PML-RARA gene in a patient with $\mathrm{t}(15 ; 17)$. Genes Chromosomes Cancer 1993; 6: 133-39.

23. Van Dongen JJ, Macintyre EA, Gabert JA. Standardized rt-PCR analysis of fusion gene transcripts from chromosome aberrations in acute leukemia for detection of minimal residual disease. Report of the BIOMED-1 Concerted Action: Investigation of minimal residual disease in acute leukemia. Leukemia 1999; 13: 1901-28.

24. Chen Z, Brand NJ, Chen A, Chen SJ Tong JH, Wang ZY, Waxman S, Zelent A. Fusion between a novel Krüppel-like zinc finger gene and the retinoic acid receptor-alpha locus due to a variant $t(11 ; 17)$ translocation associated with acute promyelocytic leukemia. EMBO 1993; 12: 1161-67.

25. Licht JD, Chomienne C, Goy A, Chen A, Scott AA, Head DR, Michaux JL Wu Y, DeBlasio A, Miller WH Jr. Clinical and molecular characterization of a rare syndrome of acute promyelocytic leukemia associated with translocation $(11 ; 17)$. Blood 1995; 85: 1083-94.

26. National Comprehensive Cancer Network (NCCN) practice guidelines for acute myeloid leukemia Version $1,2007$.

27. Suzuki H, Imaizumi M, Sato A, Yoshinari M, Rikiishi T, Endo M, Takano T, Shimizu T, Hatae Y, Fujimoto $\mathrm{T}$, Hayashi $\mathrm{Y}$, Iinuma K. Monitoring of minimal residual disease in children with acute promyelocytic leukemia by rt-PCR detecting PML/RAR alpha chimeric gene: A retrospective study of clinical feasibility. Tohoku J Exp Med. 2001; 193: 127-39.

28. Ikeda K, Sasaki K, Tasaka T, Nagai M, Kawanishi K, Takahara J, Irino S. Reverse transcription-polymerase chain reaction for PML-RAR $\alpha$ fusion transcripts in acute promyelocytic leukemia and its application to minimal residual leukemia detection. Leukemia 1993; 7: $544-48$

29. Miller WH Jr, Levine K, DeBlasio A, Frankel SR, Dmitrovsky E, Warrell RP Jr. Detection of minimal residual disease in acute promyelocytic leukemia by a reverse transcription polymerase chain reaction assay for the PML/RAR $\alpha$ fusion mRNA. Blood 1993; 82: 1689-94.

30. Miller WH Jr, Kakizuka A, Frnkel SR, Warrell RP Jr, Deblasio A, Levine K, Evans RM, Dmitrovsky E. Reverse transcription polymerase chain reaction for the rearranged retinoic acid receptor alpha clarifies diagnosis and detects minimal residual disease in acute promyelocytic leukemia. Proc Natl Acad Sci USA 1992; 89: 2694-98.

31. Radich JP, Gooley T, Bryant E, Chauncey T, Clift R, Beppu L, Edmands S, Flowers ME, Kerkof K, Nelson $\mathrm{R}$, Appelbaum FR. The significance of BCR-ABL molecular detection in chronic myeloid leukemia patients "late," 18 months or more after transplantation. Blood 2001; 98: 1701-07

32. National Comprehensive Cancer Network (NCCN) practice guidelines for chronic myelogenous leukemia. Version 1, 2008.

33. Hughes $\mathrm{T}$, Deininger M, Hochhaus A, Branford S, Radich J, Kaeda J, Baccarani M, Cortes J, Cross NCP, Druker BJ, Gabert J, Grimwade D, Hehlmann R, Kamel-Reid S, Lipton JH, Longtine J, Martinelli G, Saglio G, Soverini S, Stock W, Goldman JM. Monitoring CML patients responding to treatment with tyrosine kinase inhibitors: Review and recommendations for harmonizing current methodology for detecting BCR-ABL transcripts and kinase domain mutations and for expressing results. Blood 2006; 108: 28-37. 